\title{
Optimal Allocation of DG and D-STATCOM in a Distribution System using Evolutionary based Bat Algorithm
}

\author{
Surender Reddy Salkuti \\ Department of Railroad and Electrical Engineering \\ Woosong University, Daejeon, South Korea
}

\begin{abstract}
In this work, a methodology to find the optimal allocation (i.e., sizing and location) of Distributed Generators (DGs) and Distribution-static compensators (D-STATCOM) in a radial distribution system (RDS) is proposed. Here, the voltage stability index (VSI) is utilized to find the optimal location for the D-STATCOM, and loss sensitivity factor (LSF) method is utilized to find the optimal location for distributed generation. In this work, the proposed work is formulated as a non-linear optimization problem and it is solved using the metaheuristic/evolutionary-based algorithm. The evolutionary-based Bat algorithm is used to find optimal sizes of D-STATCOM and DGs in RDSs. To check the validity and feasibility and validity of the proposed optimal allocation approach, two standard IEEE 34 and 85 bus RDSs are considered in this paper. The simulation results show reduction in power losses and enhancement in bus voltages in the RDSs.
\end{abstract}

Keywords-Bat algorithm; distributed generation; voltage stability index; loss sensitivity; optimal location and size; radial distribution system

\section{NOMENCLATURE}

\begin{tabular}{|c|c|}
\hline$V_{i}$ & Voltage magnitude at $i^{\text {th }}$ bus. \\
\hline BIBC & Bus current Injection to Branch Current matrix \\
\hline iter & Iteration number. \\
\hline iter $_{\max }$ & Maximum number of iterations. \\
\hline$N_{b}$ & Number of buses. \\
\hline$V_{i+1}$ & Voltage magnitude at $(\mathrm{i}+1)^{\text {th }}$ bus. \\
\hline$\varepsilon$ & Equally distributed number between -1 and 1 . \\
\hline$A_{i}^{k}$ & Average loudness of all bats in the $\mathrm{k}^{\text {th }}$ iteration. \\
\hline$Z_{i}$ & Pulse emission rate of $i^{\text {th }}$ Bat. \\
\hline$\omega$ & Inertia weight factor. \\
\hline$R_{i,(i+1)}$ & Resistance between the buses $i$ and $(i+1)$. \\
\hline$X_{i,(i+1)}$ & Reactance between the buses $i$ and $(i+1)$. \\
\hline$P_{D i}, Q_{D i}$ & $\begin{array}{l}\text { Active and reactive power demands at } \mathrm{i}^{\text {th }} \text { bus. } \\
\text { Current flow in the line. }\end{array}$ \\
\hline$P_{D S}$ & Power supplied from the RDS. \\
\hline$P_{D-S T A T C O M}$ & Active power from the D-STATCOM. \\
\hline $\boldsymbol{S}^{*}$ & Global solution. \\
\hline$P_{D G}$ & Power output from the DG. \\
\hline$r$ & Pulse emission rate. \\
\hline $\boldsymbol{\beta}$ & Random number between 0 and 1 . \\
\hline$f_{\min }^{\min }, f_{\max }$ & Minimum and maximum frequencies. \\
\hline
\end{tabular}

\section{INTRODUCTION}

In recent years, renewable energy is gaining huge attention throughout the world because of several reasons. The increased awareness towards renewable and sustainable energies, such as wind and solar energies has stimulated the trend towards energy-efficient devices and energy conservation techniques to optimize the energy demand and cost-saving. The distribution networks acquire higher losses (i.e., around 13\%) in the entire power system, and the voltage stability issues of radial distribution systems (RDSs) have to be considered urgently. From the planning perspective, the optimal operating of the distribution system is used for shunt volt-ampere reactive planning, series capacitor planning, transfer capability Studies, reactive interchange studies, loss optimization studies. Distributed generation (DG) from various sources offers an economic and reliable source of electricity to the customers. Optimal integration of distributed generation into an existing power network plays a vital role because of its benefits. Optimal DG allocation (i.e., location and sizing) is the challenging issue to improve system efficiency by reducing the power losses and by improving the voltage stability and security of the system. D-STATCOM is used for reactive power compensation, which in turn minimizes voltage drop and power losses that are caused by the increasing demands [1]. The optimal solution is obtained after solving several power flow solutions, corresponding to a specified set of consumer demands.

With the advancement of smart grid technologies, managing the distribution network safely and economically has been one of the major business activities of an electrical utility. One of the fundamental issues is that the energy transferred by the network is continually changing as the consumer load changes; in addition to this, the network itself is not static [2]. Long-term planning studies are carried out for several years ahead to check the resilience of the existing networks for various situations. Power system analysis tools including optimization studies are used to design construction or refurbishment of plant for further expansion. Although an optimal running arrangement for an expected load pattern may be determined in a planning study, this may not match the system conditions on that day [3].

The author in [4] illustrates the importance of optimal sizing and location of DG in RDS. The author in [5] utilizes 
an analytical-based method for finding the optimal size and location of D-STATCOM and DG placement in RDS. A methodology for the optimal sizing D-STATCOM in RDSs considering load demand uncertainty is presented in [6]. A fuzzy-based approach for feeder reconfiguration considering D-STATCOM to reduce operating cost and active power losses in RDSs has been proposed in [7]. An optimal placement approach using multi-objective-based sensitivity methodology and evolutionary-based technique for determining the optimal allocation of D-STATCOM in unbalanced RDS is described in [8]. An approach to find the optimal sizing of DGs in RDSs with uncertain topologies is solved using Monte Carlo Simulation (MCS) is proposed in [9]. An approach to finding optimal sizing and placement of DG and D-STATCOM is analyzed in [10] to optimize power loss, costs, and voltage profile enhancement in the RDS.

Nowadays, evolutionary techniques have been used for different applications of distribution systems (DSs). An approach to find the optimal location and sizing of DSTATCOM and DG to optimize power losses of the system using Harmony search algorithm (HSA) is presented in [11], using Cuckoo search algorithm (CSA) is presented in [12], using invasive weed optimization technique is presented in [13], using Stud Krill herd technique is presented in [14], using backtracking search optimization (BSO) technique is presented in [15], using Ant Lion optimization (ALO) algorithm is presented in [16], using improved differential search algorithm is presented in [17], using whale optimization algorithm (WOA) is described in [18]-[19], using the particle swarm optimization (PSO) is presented in [20].

An efficient optimization approach is required for the adjustment of control variables in the optimization. Due to various limitations of classical optimization algorithms, in the present work evolutionary algorithms are used as an optimization tool. Artificial neural networks find applications in power system planning, operation, and analysis. Some of the applications are in load forecasting, optimal power flow, unit commitment, state estimation, static and dynamic security assessment, fault detection, fault location, system voltage stability assessment. Fuzzy systems find applications in power system planning, operation, and control. A few of the applications include generation expansion planning, reliability analysis, daily load forecasting, voltage, and reactive power control, state estimation, security assessment, fault diagnosis, converters control, and various control systems design. In this work, bat algorithm (BA) is used for solving the optimal location and sizing of D-STATCOMs and DGs in RDSs. The voltage stability index (VSI) is considered for finding the optimal location to install D-STATCOM, and loss sensitivity factor (LSF) method for determining an optimal location to install DG.

\section{PROBLEM FormULATION}

\section{A. Distribution Load Flow (DLF)}

Here, a direct approach is utilized to solve the distribution load flow (DLF), which gives the voltage at each bus and total power losses in the RDS. Fig. 1 depicts the single-line diagram (SLD) of two buses in RDS [21].

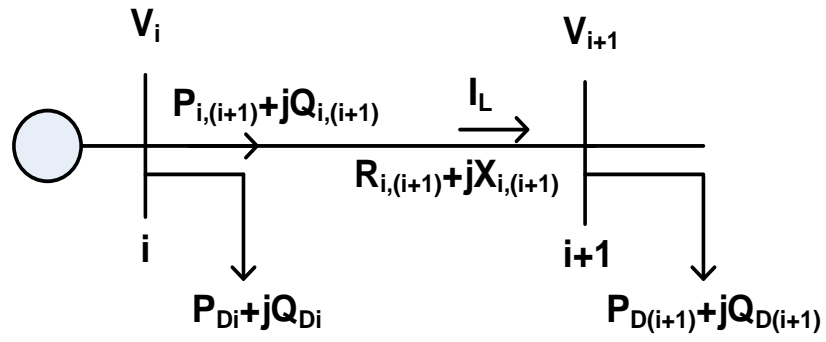

Fig. 1. SLD of Two Buses in Radial Distribution System (RDS).

From Fig. 1, voltage at the bus (i+1) is expressed as [22],

$V_{i+1}=V_{i}-I_{L}\left[R_{i,(i+1)}+j X_{i,(i+1)}\right]$

The branch current $I_{L}$ is expressed as

$I_{L}=[B I B C][i]$

From Fig. 1, the injected current at the $i^{\text {th }}$ bus is expressed as [23],

$I_{L}=\left(\frac{P_{D i}+j Q_{D i}}{V_{i}}\right)^{*}$

The active power loss between buses $i$ and $(i+1)$ can be calculated by using the load flow solution and it is expressed as [24],

$P_{\text {loss }(i,(i+1))}=\left(\frac{P_{i,(i+1)}^{2}+Q_{i,(i+1)}^{2}}{\left|V_{i,(i+1)}\right|^{2}}\right) R_{i,(i+1)}$

Total power loss $\left(P_{T L}\right)$ of RDSs can be found by adding losses in all the lines, and it can be expressed as [25],

$P_{T L}=\sum_{i=1}^{N_{b}} P_{\text {loss }(i,(i+1))}$

The D-STATCOM also injects the reactive power into the power network. The detailed modeling of D-STATCOM incorporated in the load flow study has been presented in [26]. The detailed description of VSI is presented in references [2728], and the description of LSF is presented in references [2930].

\section{B. Objective Function: Minimization of Active Power Losses}

The main concentration of the work is the development of more robust and faster optimal allocation approach. Load flow solution is a part of optimal power flow solution which is considered as the equality constraint of the optimal allocation problem. Power flow is the most fundamental numerical algorithm for the analysis of distribution network. The cost minimization objective is mainly influenced by the variables that mostly influence the cost minimization are active power generations of generators, voltage magnitude of generators. For loss minimization objective the active power generations almost at maximum values. Voltage magnitudes of generators, transformer taps and shunts all influence loss. This objective function plays a major role in RDSs. This objective function can be formulated as [31],

minimize $J_{1}=\operatorname{minimize}\left(P_{T L}\right)$ 


\section{Equality Constraints}

This constraint represents the power balance among the total power generation from the DS, DG, and D-STATCOM, and the system load plus losses. Mathematically, this constraint can be modeled as [32],

$\sum_{i=1}^{N_{b}} P_{D i}+P_{T L}=P_{D G}+P_{D-S T A T C O M}+P_{D S}$

\section{Inequality Constraints}

These constraints on control parameters are so selected that they fall within the permissible limits. Then the functional inequality constraints are considered using the penalty method, where the objective function is augmented by a penalty term, for each violated functional constraint. The limitation of the method is in the modeling of transformer taps [33].

\section{1) Constraint on Bus Voltage Magnitudes}

Voltage magnitude at each bus is restricted by [34],

$V_{i}^{\min } \leq\left|V_{i}\right| \leq V_{i}^{\max }$

\section{2) Reactive Power Compensation (RPC) Constraint}

Reactive power $\left(Q_{D-S T A T C O M}\right)$ injected by the D-STATCOM at $\mathrm{i}^{\text {th }}$ candidate bus is limited by [35],

$Q_{D-S T A T C O M, i}^{\min } \leq Q_{D-S T A T C O M, i} \leq Q_{D-S T A T C O M, i}^{\max }$

\section{3) Active Power Constraint}

Real power injected by DG at $\mathrm{i}^{\text {th }}$ bus is limited by [36, 37],

$P_{D G, i}^{\min } \leq P_{D G, i} \leq P_{D G, i}^{\max }$

\section{BAT ALGORITHM}

The BA is inspired by echolocation ability of the microbats [38]. Suppose a Bat has a randomly generated position of $S_{i}$ and the velocity of $V_{i}$. Here, the Bat is selected based on the sound pulses that emits with a loudness of $A_{0}$, charging wavelength of $\lambda$, the fixed minimum frequency of $f_{\text {min }}$, and $r$ is a random number that takes a value in the range $[0,1]$.

BA develops the potential candidate solutions as the virtual microbats with velocities $\left(V_{i}\right)$, positions $\left(S_{i}\right)$, and frequencies $\left(f_{i}\right)$, and they are restructured as [39],

$f_{i}=\left(f_{\max }-f_{\min }\right) \beta+f_{\min }$

$V_{i}^{k+1}=V_{i}^{k}+\left(S_{i}^{k}-S^{*}\right) f_{i}$

where $\mathrm{k}$ is number of iterations, and $i$ is number of Bats.

$S_{i}^{k+1}=S_{i}^{k}+V_{i}^{k+1}$

The new position is updated using,

$S_{i, \text { new }}^{k}=S_{i, \text { old }}^{k}+\varepsilon A_{i}^{k}$

In each iteration/generation, $\mathrm{A}_{\mathrm{i}}$ and $\mathrm{Z}_{\mathrm{i}}$ are formulated as,

$A_{i}^{k+1}=\rho A_{i}^{k}$

$Z_{i}^{k+1}=Z_{i}^{0}\left(1-e^{-\delta k}\right)$ where $\delta$ and $\rho$ are the constants, where $0<\rho<1, \delta>0$. Bat's velocity is updated using $\omega$, and it can be represented by [40],

$V_{i}^{k+1}=\omega V_{i}^{k}+\left(S^{*}-S_{i}^{k}\right) f_{i}$

The flow chart of the Bat algorithm (BA) for the implementation of proposed optimization problem is depicted in Fig. 2.

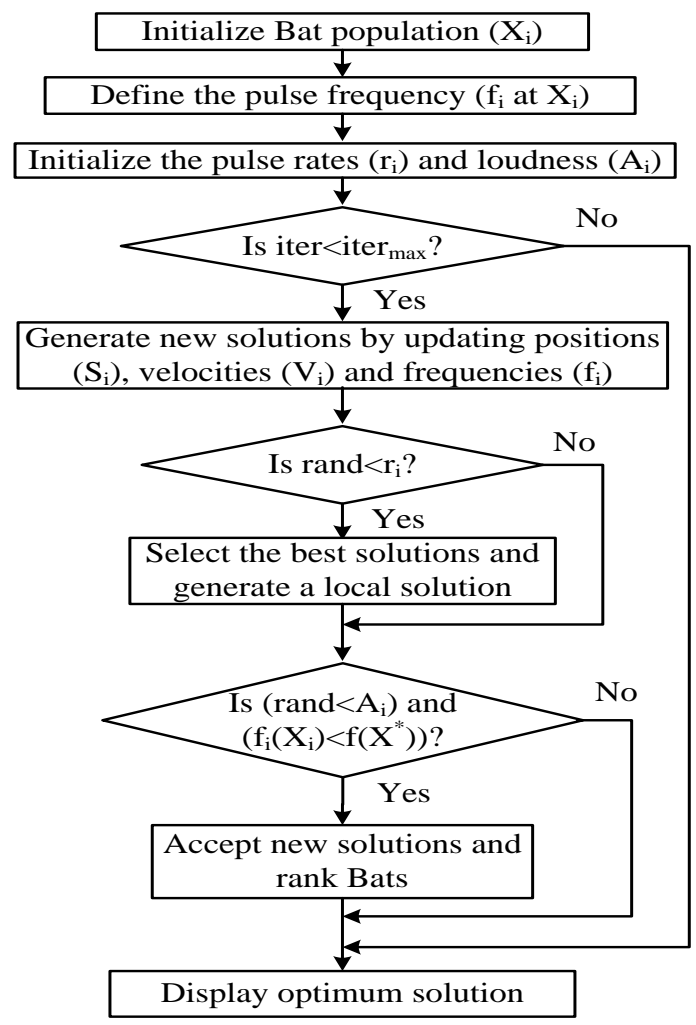

Fig. 2. Flow Chart of Bat Algorithm (BA).

Implementation of the proposed methodology is described below:

- Step 1: Input the bus data, load data of RDS, data related to Bat algorithm.

- Step 2: Perform the distribution load flow (DLF) for the base case condition (i.e., without DG and DSTATCOM), and find bus voltages, total power losses, loss sensitivity factors (LSF), and voltage stability index (VSI).

- Step 3: Find optimal locations for placing DGs using the LSF approach and D-STATCOM using VSI.

- Step 4: Initialize the random Bat algorithm $\left(X_{i}\right)$ for the amount of kW's and kVAr's to be injected within their minimum and maximum limits.

- Step 5: Generate a new solution by adjusting the frequencies $\left(f_{i}\right)$ using equation (11). Update positions $\left(S_{i}^{k+1}\right)$ and velocities $\left(v_{i}^{k+1}\right)$ using the equations (12) and (13). 
- Step 6: Calculate fitness function using objective function (i.e., Equation (6)) for each Bat location.

- Step 7: Generate a random number using the rand function. If rand $>$ pulse rates $\left(r_{i}\right)$, then determine a local solution near the best solution using the equation (17). Otherwise, go to Step 10.

- Step 8: Check if $\left(\operatorname{rand}<A_{i}\right)$ and $f\left(X_{i}\right)<f\left(X^{*}\right)$. If YES, then accept new solutions, reduce $A_{i}$, and increase $r_{i}$ then update the current best solution. If NO, then set the best solution as the current best solution.

- Step 9: Check the stopping criteria. If (iter<iter $r_{\max }$ ), then go to Step 5, else STOP the algorithm.

- Step 10: Print the optimal solution.

\section{Simulation Results AND Discussion}

In this work, IEEE 34 bus and 85 bus RDSs are selected to check the validity of proposed optimal allocation methodology. For each RDS, 3 case studies are simulated, and they are:

- Case 1: Base case condition, i.e., system without DG and D-STATCOM.

- Case 2: System with single DG and D-STATCOM.

- Case 3: System with multiple DGs and D-STATCOMs.

\section{A. Results on IEEE 34 bus RDS}

The bus data and line data of 34 buses, 33 branch RDS is selected from [41].

1) Case study 1: Base Case (without D-STATCOM and $D G)$ : In this case study, the base case is considered without installing the D-STATCOM and DG. Here, the obtained optimal real power loss is $221.67 \mathrm{~kW}$ and reactive power loss is $65.1 \mathrm{kVAr}$, and they are presented in Table I. The voltage profile of 34 bus RDS for case study 1 is depicted in Fig. 3. The minimum voltage in the system is $0.9355 \mathrm{p}$.u. and it is at bus number 27. And also minimum VSI obtained is 0.7875 p.u.

2) Case study 2: Network with single DG and DSTATCOM: Here, single D-STATCOM and DG are installed simultaneously at optimal places to achieve optimum objectives. Simulation results obtained in this case are presented in Table I. Here, the obtained optimal placement of DG at bus number 21 and its optimal size is $2154.75 \mathrm{~kW}$. By using the proposed approach, bus number 22 is obtained as the suitable location for installing the D-STATCOM, and its size is $1250.8 \mathrm{kVAr}$. Here, the obtained optimal active power loss is $56.45 \mathrm{~kW}$ and it is $74.53 \%$ less compared to the loss obtained in case study 1. Table I and Fig. 3 depict the optimal allocation of DG and D-STATCOMs, and voltage profile at each bus. In this case, the minimum voltage obtained is 0.9756 p.u., which has been improved, compared to case study 1 (i.e., 0.9355 p.u.). In similar lines, minimum VSI obtained in this case is 0.9118 p.u. which is also improved as compared to case study 1 (i.e., 0.7875 p.u.).
TABLE I. OBTAINED RESULTS FOR IEEE 34 BUS RDS

\begin{tabular}{|l|l|l|l|}
\hline & $\begin{array}{l}\text { Case } \\
\text { study 1 }\end{array}$ & $\begin{array}{l}\text { Case } \\
\text { study 2 }\end{array}$ & Case study 3 \\
\hline $\begin{array}{l}\text { Optimal size and } \\
\text { location of DGs }\end{array}$ & --- & $\begin{array}{l}2154.75 \\
\mathrm{~kW} \text { at bus } \\
21\end{array}$ & $\begin{array}{l}1820.53 \mathrm{~kW} \text { at bus } 21 \\
763.11 \mathrm{~kW} \text { at bus 32 } \\
102.07 \mathrm{~kW} \text { at bus 34 }\end{array}$ \\
\hline $\begin{array}{l}\text { Optimal size and } \\
\text { location of D- } \\
\text { STATCOM }\end{array}$ & --- & $\begin{array}{l}1250.8 \\
\mathrm{kVAr} \text { at } \\
\text { bus 22 }\end{array}$ & $\begin{array}{l}960.82 \mathrm{kVAr} \text { at bus } 18 \\
618.51 \mathrm{kVAr} \text { at bus 22 }\end{array}$ \\
\hline$V_{\min }$ (p.u.) & 0.9355 & 0.9756 & 0.9912 \\
\hline VSI $I_{\text {min }}$ (p.u.) & 0.7875 & 0.9118 & 0.9701 \\
\hline $\begin{array}{l}\text { Optimum power } \\
\text { loss (kW) }\end{array}$ & $\mathbf{2 2 1 . 6 7}$ & $\mathbf{5 6 . 4 5}$ & $\mathbf{1 8 . 9 4}$ \\
\hline Loss reduction (\%) & --- & 74.53 & 91.46 \\
\hline
\end{tabular}

3) Case study 3: System with multiple DGs and DSTATCOMs: Here, multiple D-STATCOMs and DGs are allocated in the system and results are reported in Table I. In this case study, it has been considered that three DGs and two D-STATCOMs are placed in the RDS. The suitable locations of DGs obtained are at buses 21, 32, 34, and their optimal sizes are $1820.53 \mathrm{~kW}, 763.11 \mathrm{~kW}$, and $102.07 \mathrm{~kW}$, respectively. Optimal locations obtained for D-STATCOM are buses 18, 22 and their optimal sizes are 960.82 kVAr, 618.51 $\mathrm{kVAr}$, respectively. The obtained minimum power loss is $18.94 \mathrm{~kW}$ and it is $91.46 \%$ less when compared to case study 1 and $66.45 \%$ less when compared to case study 2. Minimum voltage obtained is 0.9912 p.u., which has been improved from case study 1 (i.e., 0.9355 p.u.) and case study 2 (i.e., 0.9756 p.u.). Minimum VSI obtained is 0.9701 p.u., which has been improved from case study 1 (i.e., 0.7875 p.u.) and case study 2 (i.e., 0.9118 p.u.).

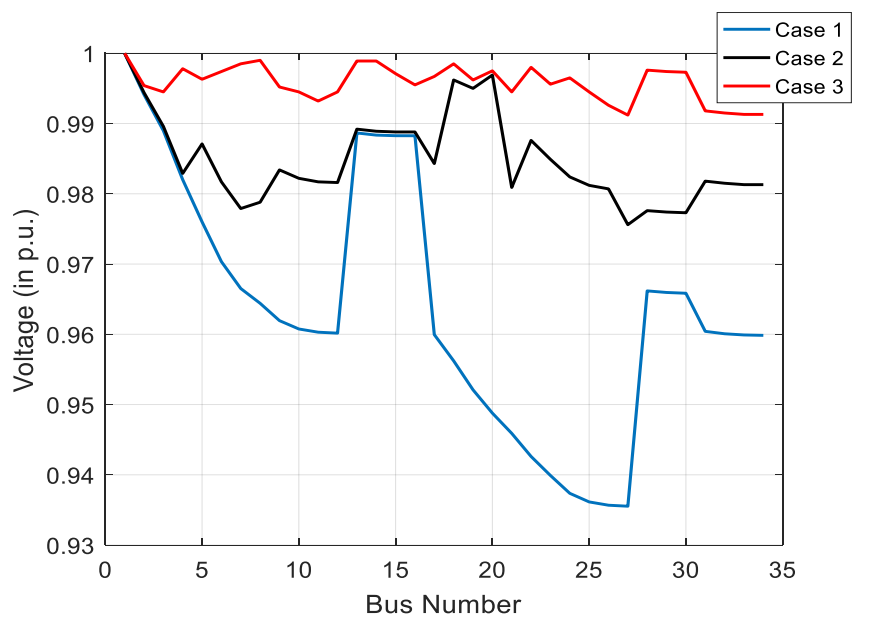

Fig. 3. Voltage Profile of 34 Bus RDS for Cases 1, 2, and 3.

\section{B. Results on IEEE 85 bus RDS}

The bus data and line data of 85 bus, 84 branch RDS is selected from [42].

1) Case study 1: Base Case (without D-STATCOM and $D G)$ : In this case study, the base case is considered without installing the D-STATCOM and DG. The obtained optimal 
active power loss is $315.70 \mathrm{~kW}$ and reactive loss is 198.356 $\mathrm{kVAr}$, and they are presented in Table II. Voltage profile of 85 bus RDS for case study 1 is depicted in Fig. 4 . The minimum voltage in the system is 0.8714 p.u. and it is a bus number 54 . And also the obtained minimum VSI is 0.6713 p.u.

\section{TABLE II. OBTAINED RESULTS FOR IEEE 85 BUS RDS}

\begin{tabular}{|l|l|l|l|}
\hline & Case 1 & Case 2 & Case 3 \\
\hline $\begin{array}{l}\text { Optimal size and location } \\
\text { of DG }\end{array}$ & --- & $\begin{array}{l}2371.4 \\
\mathrm{~kW} \text { at } \\
\text { bus 55 }\end{array}$ & $\begin{array}{l}359.4 \mathrm{~kW} \text { at bus } 8 \\
680.3 \mathrm{~kW} \text { at bus } 29 \\
2250.7 \text { at bus 55 }\end{array}$ \\
\hline $\begin{array}{l}\text { Optimal size and location } \\
\text { of D-STATCOM }\end{array}$ & --- & $\begin{array}{l}1185.6 \\
\mathrm{kVAr} \text { at } \\
\text { bus 58 }\end{array}$ & $\begin{array}{l}692.1 \mathrm{kVAr} \text { at bus 27 } \\
1079.8 \mathrm{kVAr} \text { at bus } 58\end{array}$ \\
\hline$V_{\text {min }}$ (p.u.) & 0.8714 & 0.9346 & 0.9704 \\
\hline$V S I_{\text {min }}$ (p.u.) & 0.6713 & 0.8631 & 0.9240 \\
\hline $\begin{array}{l}\text { Optimum power loss } \\
\text { (kW) }\end{array}$ & $\mathbf{3 1 5 . 7 0}$ & $\mathbf{8 2 . 3 6}$ & $\mathbf{3 1 . 9 4}$ \\
\hline Loss reduction $(\%)$ & --- & 73.91 & 89.88 \\
\hline
\end{tabular}

2) Case study 2: System with single D-STATCOM and DG: Here, single DG and D-STATCOMs are located simultaneously at optimal places to achieve optimum objectives, i.e., improving the voltage profile or minimizing the power losses. The obtained results are presented in Table II. Here, the obtained optimal placement of DG at bus number 55 and its optimal size is $2371.4 \mathrm{~kW}$. By using the proposed approach, bus number 58 is obtained as optimal location for D-STATCOM, and its optimal size is 1185.6 $\mathrm{kVAr}$. The optimal active power loss obtained is $82.36 \mathrm{~kW}$ and it is $82.36 \%$ less compared to the loss obtained in case study 1. Table II and Fig. 4 depict optimal sizes and locations of DG and D-STATCOMs and the voltage profile at each bus. The obtained minimum voltage is 0.9346 p.u., which has been improved, compared to case study 1 (i.e., 0.8714 p.u.). In similar lines, the obtained minimum VSI is 0.8631 p.u. which is also improved as compared to case study 1 (i.e., 0.6713 p.u.).

3) Case study 3: System with multiple DGs and DSTATCOMs: Here, multiple D-STATCOMs and DGs are located in the system and the results are reported in Table II. In this case study, it has been considered that three DGs and two D-STATCOMs are placed in the network. Optimal locations of DGs obtained are at buses 8, 29, 55, and their optimal sizes are $359.4 \mathrm{~kW}, 680.3 \mathrm{~kW}$, and $2250.7 \mathrm{~kW}$, respectively. Optimal locations of D-STATCOM are at buses 27, 58 and their optimal sizes are $692.1 \mathrm{kVAr}, 1079.8 \mathrm{kVAr}$, respectively. Here, the obtained minimum loss is $31.94 \mathrm{~kW}$ and it is $89.88 \%$ less when compared to case study 1 and $61.22 \%$ less when compared to case study 2. Minimum voltage obtained is 0.9704 p.u., and it has been improved from case study 1 (i.e., 0.8714 p.u.) and case study 2 (i.e., 0.9346 p.u.). Minimum VSI obtained is 0.9240 p.u., which has been improved from case study 1 (i.e., 0.6713 p.u.) and case study 2 (i.e., 0.8631 p.u.).

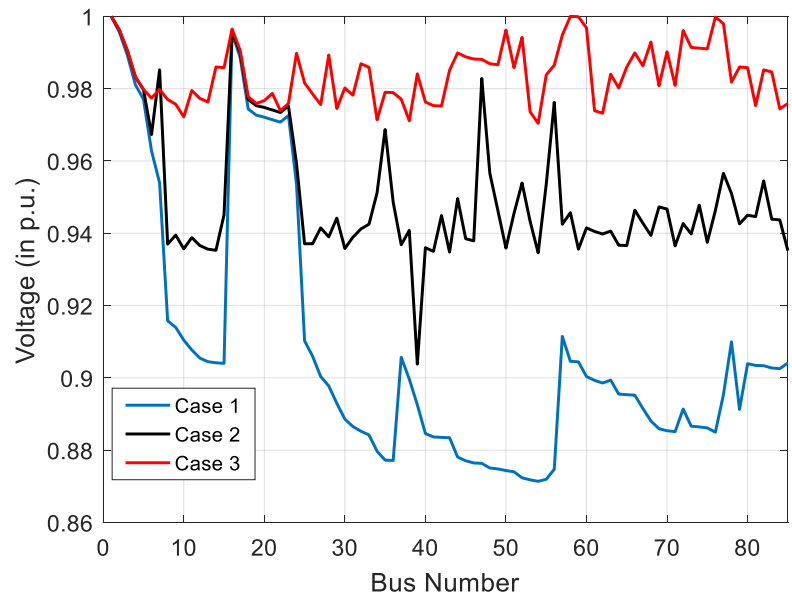

Fig. 4. Voltage Profile of 85 Bus RDS for Cases 1, 2, and 3.

\section{CONClusions}

Optimal allocation that is sizing and location of DSTATCOM and DG problem have been solved in this paper to optimize system losses and to enhance voltage profile of the radial distribution systems (RDSs). In this work, loss sensitivity factor (LSF) method is utilized to find suitable location for the DG, and voltage stability index (VSI) is utilized to determine the suitable location for the DSTATCOM. Bat algorithm (BA) is used for determining optimal sizing of DG and D-STATCOM in RDSs. The validity of the proposed optimization problem is examined on IEEE 34 bus and 85 bus RDSs. Simultaneous allocation of DGs and D-STATCOMs in RDSs reduces power losses and enhances the voltage profile in the RDS. Future work can be extended for finding the optimal locations for the electric vehicles charging stations.

\section{ACKNOWLEDGMENT}

This research work was funded by "Woosong University's Academic Research Funding - 2021".

\section{REFERENCES}

[1] Y. Thangaraj, R. Kuppan, "Multi-objective simultaneous placement of DG and DSTATCOM using novel lightning search algorithm", Journal of Applied Research and Technology, vol. 15, pp. 477-491, 2017.

[2] T.P. Nguyen, D.N. Vo, T.T. Tran, “Optimal Number, Location, and Size of Distributed Generators in Distribution Systems by Symbiotic Organism Search Based Method", Advances in Electrical and Electronic Engineering, vol. 15, no. 5, pp. 724-735, Dec. 2017.

[3] S.R. Salkuti, "Optimal Location and Sizing of Shunt Capacitors with Distributed Generation in Distribution Systems", ECTI Transactions on Electrical Engineering, Electronics, and Communications, vol. 19, no. 1, pp. 34-42, Feb. 2021.

[4] S.S. Kola, "A Review on Optimal Allocation and Sizing Techniques for DG in Distribution Systems", International Journal of Renewable Energy Research, vol. 8, no. 3, pp. 1236-1256, Sept. 2018.

[5] B. Weqar, M.T. Khan, A.S. Siddiqui, "Optimal Placement of Distributed Generation and D-STATCOM in Radial Distribution Network", Smart Science, vol. 6, no. 2, pp. 125-133, 2018.

[6] E. Shahryari, H. Shayeghi, M.M oradzadeh, "Probabilistic and MultiObjective Placement of D-STATCOM in Distribution Systems Considering Load Uncertainty", Electric Power Components and Systems, vol. 46, no. 1, pp. 27-42, 2018.

[7] M. Mohammadi, M. Abasi, A.M. Rozbahani, "Fuzzy-GA based algorithm for optimal placement and sizing of distribution static 
compensator (DSTATCOM) for loss reduction of distribution network considering reconfiguration", Journal of Central South University, vol. 24, no. 2, pp. 245-258, Feb. 2017.

[8] X. Su, H. Liu, Y. Fu, P. Wolfs, "Multi-objective DSTATCOM placement based on sensitivity analysis and genetic algorithm in unbalanced mv distribution networks", IEEE Innovative Smart Grid Technologies - Asia (ISGT-Asia), Auckland, 2017, pp. 1-5.

[9] C.B. Donadel, J.F. Fardin, L.F. Encaracao, "Optimal Placement of Distributed Generation Units in a Distribution System with Uncertain Topologies using Monte Carlo Simulation", International Journal of Emerging Electric Power Systems, vol. 16, no. 5, pp. 431-442, Oct. 2015.

[10] K.R. Devabalaji, K. Ravi, "Optimal size and siting of multiple DG and DSTATCOM in radial distribution system using Bacterial Foraging Optimization Algorithm", Ain Shams Engineering Journal, vol. 7, pp. 959-971, 2016.

[11] T. Yuvaraj, K.R. Devabalaji, K. Ravi, "Optimal placement and sizing of DSTATCOM using Harmony Search algorithm", Energy Procedia, vol. 79, pp. 759-765, 2015.

[12] T. Yuvaraj, K. Ravi, K.R. Devabalaji, "Optimal allocation of DG and DSTATCOM in radial distribution system using Cuckoo Search optimization algorithm", Modelling and Simulation in Engineering, vol. 2017, pp. 1-11, 2017.

[13] D.R. Prabha, T. Jayabarathi, "Optimal placement and sizing of multiple distributed generating units in distribution networks by invasive weed optimization algorithm", Ain Shams Engineering Journal, vol. 7, pp. 683-694, 2016.

[14] S.A.C. Devi, L. Lakshminarasimman, R. Balamurugan, "Stud Krill herd Algorithm for multiple DG placement and sizing in a radial distribution system", Engineering Science and Technology, an International Journal, vol. 20, pp 748-759, 2017.

[15] A.E. Fergany, "Optimal allocation of multi-type distributed generators using backtracking search optimization algorithm", International Journal of Electrical Power Energy Systems, vol. 64, pp. 1197-1205, 2015.

[16] P.D.P. Reddy, V.C.V. Reddy, T.G. Manohar, "Ant Lion optimization algorithm for optimal sizing of renewable energy resources for loss reduction in distribution systems", Journal of Electrical Systems and Information Technology, vol. 5, no. 3, pp. 663-680, Dec. 2018.

[17] S.K. Injeti, "A Pareto optimal approach for allocation of distributed generators in radial distribution systems using improved differential search algorithm", Journal of Electrical Systems and Information Technology, vol. 5, no. 3, pp. 908-927, Dec. 2018.

[18] P.D.P. Reddy, V.C.V. Reddy, T.G. Manohar, "Optimal renewable resources placement in distribution networks by combined power loss index and whale optimization algorithms", Journal of Electrical Systems and Information Technology, vol. 5, no. 2, pp. 175-191, Sept. 2018.

[19] D.B. Prakash, C. Lakshminarayana, "Optimal siting of capacitors in radial distribution network using Whale Optimization Algorithm", Alexandria Engineering Journal, vol. 56, no. 4, pp. 499-509, Dec. 2017.

[20] D.B. Prakash, C. Lakshminarayana, "Multiple DG Placements in Distribution System for Power Loss Reduction Using PSO Algorithm", Procedia Technology, vol. 25, pp. 785-792, 2016.

[21] F. Iqbal, M.T. Khan, A.S. Siddiqui, "Optimal placement of DG and DSTATCOM for loss reduction and voltage profile improvement", Alexandria Engineering Journal, vol. 57, no. 2, pp. 755-765, Jun. 2018.

[22] S.R. Salkuti, "Optimal location and sizing of DG and D-STATCOM in distribution networks", Indonesian Journal of Electrical Engineering and Computer Science, vol. 16, no. 3, pp. 1107-1114, Dec. 2019.

[23] X. Su, H. Liu, Y. Fu, P. Wolfs, "Multi-objective DSTATCOM placement based on sensitivity analysis and genetic algorithm in unbalanced mv distribution networks", IEEE Innovative Smart Grid Technologies - Asia (ISGT-Asia), Auckland, New Zealand, 2017, pp. 15.

[24] N. Mohandas, R. Balamurugan, L. Lakshminarasimman, "Optimal location and sizing of real power DG units to improve the voltage stability in the distribution system using $\mathrm{ABC}$ algorithm united with chaos", Electric Power Energy Systems, vol. 66, pp. 41-52, 2015.

[25] P.D.P. Reddy, V.C.V. Reddy, T.G. Manohar, "Application of flower pollination algorithm for optimal placement and sizing of distributed generation in Distribution systems", Journal of Electrical Systems and Information Technology, vol. 3, no. 1, pp. 14-22, May 2016.

[26] M. Junjie, W. Yulong, L. Yang, "Size and Location of Distributed Generation in Distribution System Based on Immune Algorithm", Systems Engineering Procedia, vol. 4, pp. 124-132, 2012.

[27] S. Sudabattula, M. Kowsalya, "Optimal allocation of wind based distributed generators in distribution system using Cuckoo Search Algorithm", Procedia Computer Science, vol. 92, pp. 298-304, 2016.

[28] M.J.H. Moghaddam, S. Arabi-Nowdeh, M. Bigdeli, D. Azizian, “A multi-objective optimal sizing and siting of distributed generation using ant lion optimization technique", Ain Shams Engineering Journal, vol. 9, no. 4, pp. 2101-2109, Dec. 2018.

[29] S. Kansal, V. Kumar, B. Tyagi, "Hybrid approach for optimal placement of multiple DGs of multiple types in distribution networks", International Journal of Electrical Power and Energy Systems, vol. 75, pp. 226-235, 2016.

[30] B. Das, V. Mukherjee, D. Das, "DG placement in radial distribution network by symbiotic organism search algorithm for real power loss minimization", Applied Soft Computing, vol. 49, pp. 920-936, Dec. 2016.

[31] U. Sultana, A.B. Khairuddin, A.S. Mokhtar, N. Zareen, B. Sultana, "Grey wolf optimizer based placement and sizing of multiple distributed generation in the distribution system", Energy, vol. 111, pp. 525-536, 2016.

[32] M. Darfoun, M.E. El-Hawary, "Multi-objective optimization approach for optimal distributed generation sizing and placement", Electric Power Components and Systems, vol. 43, no. 7, pp. 828-836, 2015.

[33] N. Kaur, S.K. Jain, "Multi-Objective Optimization Approach for Placement of Multiple DGs for Voltage Sensitive Loads", Energies, vol. 10, pp. 1-17, 2017.

[34] A. Uniyal, A. Kumar, "Optimal Distributed Generation Placement with Multiple Objectives Considering Probabilistic Load", Procedia Computer Science, vol. 125, pp. 382-388, 2018.

[35] K.R. Devabalaji, K. Ravi, "Optimal size and siting of multiple DG and DSTATCOM in radial distribution system using Bacterial Foraging Optimization Algorithm", Ain Shams Engineering Journal, vol. 7, no. 3, pp. 959-971, Sept. 2016.

[36] A.Y. Abdelaziz, S.F. Mekhamer, R.H. Shehata, "Solution of distributed generation allocation problem using a novel method", Indonesian Journal of Electrical Engineering and Computer Science, vol. 15, no. 2, pp. 554-564, Aug. 2019.

[37] T. Yuvaraj, K. Ravi, "Multi-objective simultaneous DG and DSTATCOM allocation in radial distribution networks using cuckoo searching algorithm", Alexandria Engineering Journal, vol. 57, no. 4, pp. 2729-2742, Dec. 2018.

[38] H. Delkhosh Abatari, M. S. S. Abad and H. Seifi, Application of bat optimization algorithm in optimal power flow, 24th Iranian Conference on Electrical Engineering (ICEE), Shiraz, 2016, pp. 793-798.

[39] B.V. Rao, G.V.N. Kumar, "Optimal power flow by BAT search algorithm for generation reallocation with unified power flow controller", International Journal of Electrical Power \& Energy Systems, vol. 68, pp. 81-88, Jun. 2015.

[40] S.R. Salkuti, "Bat algorithm-based back propagation approach for shortterm load forecasting considering weather factors", Electrical Engineering, vol. 100, pp. 1297-1303, 2018.

[41] M. Chis, M. Salama, S. Jayaram, "Capacitor placement in distribution systems using heuristic search strategies", IEE Generation, Transmission and Distribution, vol. 144, no. 3, pp. 225-230, May 1997.

[42] M. Baran, F.F. Wu, "Optimal sizing of capacitors placed on a radial distribution system", IEEE Transactions on Power Delivery, vol. 4, no. 1, pp. 735-743, Jan. 1989. 